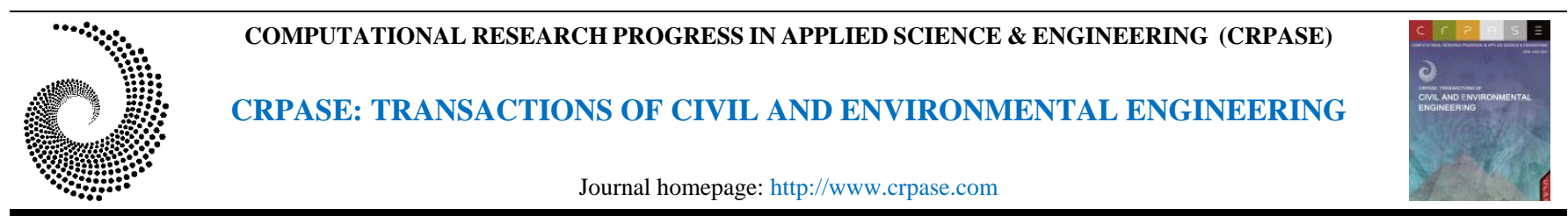

CRPASE: Transactions of Civil and Environmental Engineering 8 Article ID: 2226, 1-4, Special Issue: NCTT 2021

ISSN 2423-4591

Research Article

\title{
Accident Hotspot Detection of Exclusive Bus Transit Lanes (Case Study: City of Rasht)
}

Maziar Abolfazlzadeh ${ }^{1 *}$, Mohammad Rahmaninezhad Asil ${ }^{2}$, Zeynab Mohammadi ${ }^{3}$, Mohammad Reza Ghanbari Tamrin $^{4}$

${ }^{1}$ Department of Civil Engineering, Islamic Azad University, North Tehran Branch, Tehran, Iran

${ }^{2}$ Department of Civil Engineering, Faculty of Engineering, University of Guilan, Rasht, Iran

${ }^{3}$ Department of Civil Engineering, Shomal University, Amol, Iran

${ }^{4}$ Department of Civil Engineering, Ahrar Institute of Higher Education, Rasht, Iran

\begin{tabular}{ll}
\hline Keywords & Abstract \\
\cline { 2 - 3 } $\begin{array}{l}\text { Accident Hotspot, } \\
\text { Accident-prone Segments, }\end{array}$ & $\begin{array}{l}\text { Detecting and improving traffic accident hotspots have always been considered significantly } \\
\text { important to ensure public transport safety. Additionally, the identification of accident-prone } \\
\text { Public Transport Safety, }\end{array}$ \\
$\begin{array}{l}\text { Urban Exclusive Bus } \\
\text { sanes, Urban Accidents. }\end{array}$ & $\begin{array}{l}\text { rescue teams and emergency responses to reduce the overall casualties in urban public } \\
\text { transport-related accidents. This article analyses the various effects of exclusive bus lanes } \\
\text { in traffic accident hotspots in Rasht, the capital of Guilan province. The research included } \\
\text { eight distinguished road networks with bus exclusive transit lanes, and the appointed traffic } \\
\text { accident hotspots have been identified using IG (intensity index), EPDO (equivalent } \\
\text { property damage only), and SI (severity index) criteria. Moreover, the obtained results of } \\
\text { the current article indicate a higher frequency of accident-prone areas before 2015 (when } \\
\text { the exclusive bus lanes were initially established) compared to the following years, } \\
\text { concluding that the establishment of exclusive bus lanes can potentially reduce the overall } \\
\text { traffic accident-prone segments. }\end{array}$ \\
\hline
\end{tabular}

\section{Introduction}

In general, traffic accidents are rare, unexpected, and multivariable events that can potentially devastate human lives both financially and psychologically. Next, the transportation system of cities has a variety of sections which primarily include the three components of vehicle, human and environmental causes [1]. It should be noted that according to the World Health Organization (WHO), 1.2 million individuals are amongst the annual casualties of traffic accidents, and approximately 20-50 million are found injured each year globally. Furthermore, approximately 17,000 individuals lose their lives in Iran annually due to traffic accidents; plus, the obtained results from the city of
Rasht during a period of four years showed a total of 122 fatal and approximately 9,000 injured crash records $[2,3]$.

Contrary to the accidents, which are usually presumed to be random events, the spatial distribution of traffic accidents in the road network is not random, and areas with high traffic accident frequency are essentially called blackspots or hotspots. Besides, collisions that occur in these hotspots are often caused by either human or/and environmental factors. Additionally, the detection of such accident-prone areas is also economically viable as it can have a direct impact on reducing the frequency of deaths and injuries as well as the overall financial costs of car collisions for the general public [4-7]. Furthermore, hotspots are generally defined as areas with a length of 150-300 meters

\footnotetext{
* Corresponding Author: Maziar Abolfazlzadeh

E-mail address: maziar.abl@gmail.com
}

Received: 15 November 2021; Revised: 17 December 2021; Accepted: 14 January 2022

https://doi.org/ 10.52547/crpase.8.2226

Academic Editor: Mahdi Feizbahr

\footnotetext{
Please cite this article as: M.Abolfazlzadeh, M. Rahmaninezhad Asil, Z. Mohammadi, M.R. Ghanbari Tamrin, Accident Hotspot Detection of Exclusive Bus Transit Lanes (Case Study: City of Rasht), Computational Research Progress in Applied Science \& Engineering, CRPASE: Transactions of Civil and Environmental Engineering 8 (2022) 1-6, Article ID: 2226.
} 
of direct road [6-8] or intersections. Please note that different countries have distinguished definitions, regulations, and standards for traffic accident hotspots, which apply appropriately to the current conditions and reliability of data registration in that particular country [9]. The following
Table 1 shows a variety of definitions for accident-prone hotspots in different countries [10].

Table 1. The Various Definitions of Traffic Accident Hotspots in Different Countries

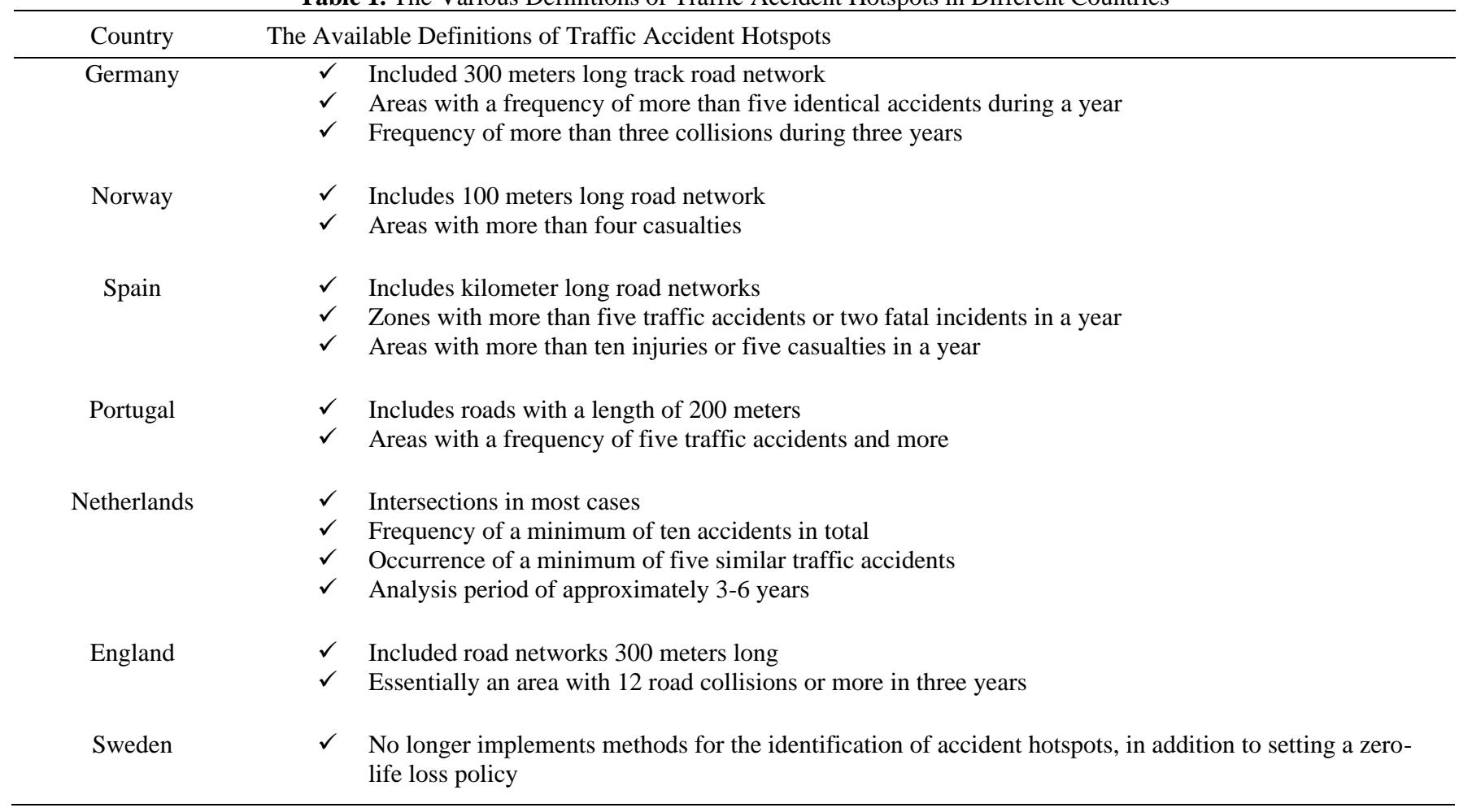

\section{Case of Study}

The current article was conducted in Rasht, the capital of Guilan province, which is generally considered one of the metropolises of Iran. Rasht is also the largest and most populated city in northern Iran. Additionally, this city is located approximately 325 kilometers from the nation's capital, Tehran. It is also essential to add that this particular city consists of an area of 180 square kilometers, located on flat land at the height of 5 meters above ocean water level and -7 meters above sea level. Next, the population of Rasht based on the obtained official census in 2011 was estimated at approximately 951,639 citizens in total, of which $50.2 \%$ are female; plus, the population density of Rash is at a rate of 4,340 citizens per square kilometer [7].

The exclusive bus lane of Imam Khomeini Street in Rasht is located between Melli Bank and Mosalla Square and was initially established in March 2015 and equipped with three public buses used for the public transportation of passengers for approximately two years. In the end, the road facilities were entirely dismantled in March 2017, primarily due to the overall dissatisfaction of the citizens with the project. Moreover, there is currently $0.1 \mathrm{~km}$ of similar remaining roads at most, which is now located between Farhang Square to Mosalla square, except other vehicles that are also officially authorized to use them simultaneously.
The following Figure 1 indicates the exact location of the road network in the current study.

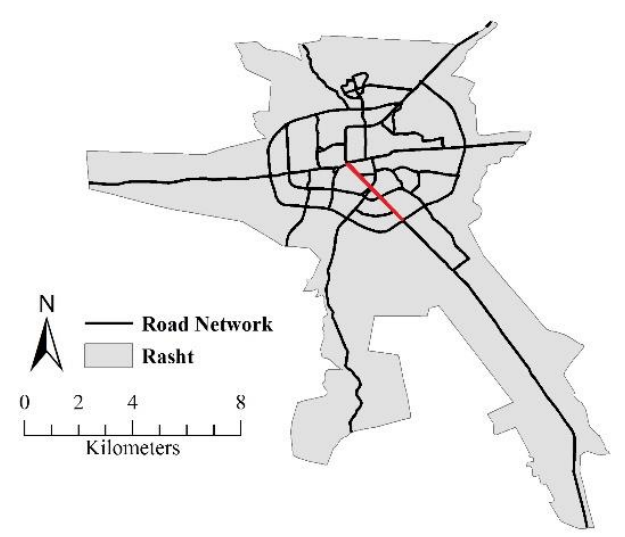

Figure 1. The Road Network of the City of Rasht.

\section{The Detection of Traffic Accident Hotspots}

The collision parameter of RSI was first used to help study the traffic accident hotspots with higher precision and accuracy to help detect the potential accident-prone locations with the highest standard for accuracy. The traffic safety index in this criterion is also essentially based on the three indicators of the severity of accidents. Furthermore, the road safety index in the current article recommended by the Portuguese Road Association primarily factors the intensity of accidents (IG), while the use of Equivalent Property 
Damage Only (EPDO) is suggested by the World Road Association (PIARC), in addition to the implementation of the Severity Index (SI) recommended by the University Transportation Center of Alabama (UTCA), which indicates the precise ratio of the type of collisions and their frequency [8].

The IG parameter essentially determines the safety index based on the relative level of accident intensity and is often defined by the Portuguese Road Association as Equation (1), in which IG is the intensity index and TA represents fatal traffic accident injuries, and TB is the total of severe road injuries, while TC shows the frequency of financial damages in car collisions. The following Eqs. (2) and (3) are applied below to obtain the indexes of EPDO and (SI), respectively.

$$
\begin{aligned}
& I G=\left(100 \times T_{-} A+10 \times T_{-} B+3 \times T_{-} C\right) \\
& E P D O=\left(5 \times T_{-} A+3 \times T_{-} B+1 \times T_{-} C\right) \\
& \mathrm{SI}=\frac{\text { Frquency of Fatally Injured } \text { Accidents }}{\text { Total Number of Traffic Accidents }}
\end{aligned}
$$

The Analytic Hierarchy Process (AHP) was initially implemented to obtain the precise weight of each index by paired comparisons. Therefore, the definition of the Relative Strength Index (RSI) is effectively defined based on the following Eq. (4)

$$
\begin{gathered}
\mathrm{RSI}=\mathrm{f}(\mathrm{IG}) \times \mathrm{W}_{\mathrm{IG}}+\mathrm{g}(\mathrm{EPDO}) \times \mathrm{W}_{\mathrm{EPDO}} \\
+\mathrm{h}(\mathrm{SI}) \times \mathrm{W}_{\mathrm{SI}}
\end{gathered}
$$

In this regard, the RSI of the finalized index of collision intensity indicate f IG, g EPDO, and h SI as standardized indicators of traffic accident severity, financial loss, and the loss of life, respectively; besides, WIG, WSI, and WEPDO approaches were also implemented to precisely weight each index accordingly. Moreover, after the development of an expert survey, the obtained data in this approach included a total of 15 traffic safety experts who participated in the survey for AHP and Multi-Criteria Decision-Making (MCDM) and the weight of each index for further use in the RSI index as shown in the Table 2.

Table 2. The Indices Weight Used to Measure the RSI Index

\begin{tabular}{cccr}
\hline Index & EPDO & IG & SI \\
\hline Weight & 0.374 & 0.482 & 0.144 \\
\hline
\end{tabular}

For this particular reason, a hierarchical structure (AHP) was initially established, and the safety variables of each hotspot were then compared in pairs, which ultimately determines their potential significance; besides, the obtained results of the conducted comparisons are effectively the required input for the Expert Choice (EC) software.

The software outcome presents the precise weight of each criterion in different buffers and their total combination, in other words, the final weight of each criterion. Additionally, one of the primary functions of this particular software is the ability to compare and determine the significance of relative buffers, so similar to the previous criteria, and the buffers should also be compared in pairs and

\begin{tabular}{|c|c|c|c|c|c|c|c|}
\hline Segment & Injury & Fatal & PDO & $\mathrm{IG}$ & EPDO & SI & RSI \\
\hline 1 & 7 & 0 & 2 & 76 & 23 & 0 & 0.45 \\
\hline 2 & 10 & 0 & 0 & 100 & 30 & 0 & 0.59 \\
\hline 3 & 3 & 0 & 1 & 33 & 10 & 0 & 0.2 \\
\hline 4 & 8 & 0 & 2 & 86 & 26 & 0 & 0.51 \\
\hline 5 & 8 & 1 & 0 & 180 & 29 & 0.013889 & 0.98 \\
\hline 6 & 4 & 0 & 1 & 43 & 13 & 0 & 0.26 \\
\hline 7 & 13 & 0 & 0 & 130 & 39 & 0 & 0.77 \\
\hline 8 & 6 & 0 & 0 & 60 & 18 & 0 & 0.36 \\
\hline
\end{tabular}
implemented as inputs into the software for the precise measurement of weight of each available buffer in the

\begin{tabular}{|c|c|c|c|c|c|c|c|}
\hline Segment & Injury & Fatal & PDO & IG & EPDO & SI & RSI \\
\hline 1 & 1 & 0 & 1 & 13 & 4 & 0 & 0.08 \\
\hline 2 & 12 & 0 & 3 & 129 & 39 & 0 & 0.77 \\
\hline 3 & 4 & 0 & 0 & 40 & 12 & 0 & 0.24 \\
\hline 4 & 6 & 0 & 2 & 66 & 20 & 0 & 0.39 \\
\hline 5 & 3 & 0 & 1 & 33 & 10 & 0 & 0.20 \\
\hline 6 & 1 & 0 & 0 & 10 & 3 & 0 & 0.06 \\
\hline 7 & 8 & 1 & 1 & 183 & 30 & 0.013889 & 0.99 \\
\hline 8 & 3 & 0 & 1 & 33 & 10 & 0 & 0.20 \\
\hline
\end{tabular}
system.

Table 3. Year 2015 (1394 Iranian Calender)

\begin{tabular}{|c|c|c|c|c|c|c|c|}
\hline Segment & Injury & Fatal & PDO & IG & EPDO & SI & RSI \\
\hline 1 & 2 & 0 & 1 & 23 & 7 & 0 & 0.14 \\
\hline 2 & 8 & 0 & 1 & 83 & 25 & 0 & 0.49 \\
\hline 3 & 3 & 0 & 3 & 39 & 12 & 0 & 0.23 \\
\hline 5 & 4 & 0 & 1 & 43 & 13 & 0 & 0.26 \\
\hline 6 & 2 & 0 & 0 & 20 & 6 & 0 & 0.12 \\
\hline 7 & 10 & 0 & 5 & 115 & 35 & 0 & 0.69 \\
\hline 8 & 4 & 0 & 1 & 43 & 13 & 0 & 0.26 \\
\hline
\end{tabular}

Table 4. Year 2016 (1395 Iranian Calender)

Table 5. Year 2017 (1396 Iranian Calender) 
The traffic accident hotspots in this particular article were officially identified and determined based on Figure 2, and the weights related to each index were implemented as an input for the software to process; plus, the obtained results were also achieved using the RSI criteria in the Tables 3 to 5. Future urban studies can be incorporated into the proposed methods to achieve more precise results [11] .

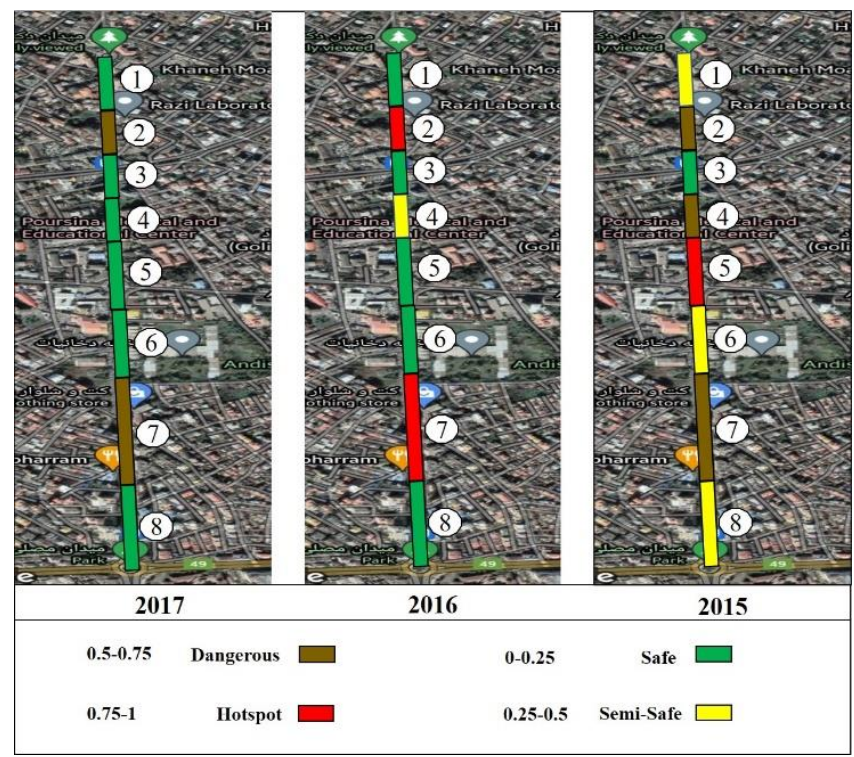

Figure 2. The hotspot identification of the study area across the three years of study.

\section{Conclusion}

The following results were obtained using the available information in Figure 2, in addition to the obtained outcome of accident-prone locations, which is presented in Table 3 to 5:

In 2015, approximately all road networks of emergency bus lanes (except for segment 3 ) were considered dangerous and amongst the potential accident-prone areas.

The construction of exclusive bus lanes in 2016 led to the reduced rate of car collisions in the street; however, traffic accidents throughout the network were primarily concentrated in one specific area with an accident-prone manner.

Segments 2 and 4 were less accident-prone (contrary to higher number of accidents in 2016) because of the populated street and the surrounding confectioneries and stores in the city.

The improvements and adjustments of the hotspots by the municipality and the discontinuation of the fences in front of segment 4 directly impacted the frequency of such incidences in 2017 compared to the two previous years.

The emergency line fences were also officially recommended for an establishment to help prevent constant pedestrian traffic in such dangerous areas, which is primarily due to the high frequency of car collisions and potential threats within the vicinity of segment 2 and 7 during the years (2015-2017).

\section{References}

[1] M. Vahedi Saheli, M. Effati, Investigation of factors contributing to pedestrian crash severity in rural roads. Journal of Injury and Violence Research 11 (2019)

[2] I. Bargegol, V. Najafi Moghaddam Gilani, M. Abolfazlzadeh, Statistical analysis of the railway accidents causes in Iran. International Journal of Engineering 30 (2017) 1822-1830.

[3] B. Dimitrijevic, S. D. Khales, R. Asadi, J. Lee, Short-Term Segment-Level Crash Risk Prediction Using Advanced Data Modeling with Proactive and Reactive Crash Data. Applied Sciences 12 (2022) 856.

[4] A. Montella, A comparative analysis of hotspot identification methods. Accident Analysis \& Prevention 42 (2010) 571581.

[5] R. Elvik, A survey of operational definitions of hazardous road locations in some European countries. Accident Analysis \& Prevention 40 (2008) 1830-1835.

[6] M. Vahedi Saheli, M. Effati, Segment-Based Count Regression Geospatial Modeling of the Effect of Roadside Land Uses on Pedestrian Crash Frequency in Rural Roads. International Journal of Intelligent Transportation Systems Research 19 (2021) 347-365.

[7] M. Effati, M. Vahedi Saheli, Examining the influence of rural land uses and accessibility-related factors to estimate pedestrian safety: The use of GIS and machine learning techniques. International Journal of Transportation Science and Technology (2021).

[8] M. Effati, H. Behbahani, S. Mortezaei, M. Vahedi Saheli, Modelling and Analyzing the Severity of Two-Lane Highway Crashes Using the Spatial Data mining, Case Study: Old Corridor of Qazvin-Loshan. Journal of Civil and Environmental Engineering (2020).

[9] S. Pourfalatoun, E. E. Miller, User perceptions of automated Truck-Mounted attenuators: Implications on work zone safety. Traffic injury prevention (2021) 1-8.

[10] I. Bargegol, V. Najafi Moghaddamgilani, A. Tahriri Amlashi, Estimation and comparison of the discharge headway according to vehicle in queue of the signalized intersection far-side legs. Journal of Civil Engineering and Structures 2 (2018) 1-12.

[11] H. Hariri Asli, M. Arabani, Y. Golpour, Reclaimed Asphalt Pavement Based on a Geospatial Information System, Slovak Journal of Civil Engineering 28 (2020) 36-42. 